\title{
Aprendizagem Baseada em Problemas e o ensino do conceito de geração de energia elétrica
}

\author{
Problem-Based-Learning and the teaching of the eletricity generation concept
}

\author{
Ana Maria Osorio Araya ${ }^{1}$ \\ Professora do departamento de Física de Ciências e Tecnologia- UNESP
}

Rodrigo Afonto La Casa de Oliveira ${ }^{2}$

Serviço Social da Industria (SESI)- Santo Anastácio

\begin{abstract}
RESUMO
Geralmente o processo de ensino aprendizagem é ineficiente quando a metodologia empregada pelo professor é pouco estimulante, razão pela qual o aluno de ensino médio é pouco motivado a estudar física. Para mudar este panorama existem atualmente metodológicas que colocam o aluno no centro do processo de ensino, sendo ele o protagonista de sua própria aprendizagem. Uma destas metodologias, utilizada nesta pesquisa, é chamada Aprendizagem Baseada em Problemas (ABP), que consiste em apresentar uma situação problema, que leva os alunos a uma análise, reflexão a apontamento de soluções para resolvê-la, em todos seus aspectos. O professor atua como orientador do processo, sendo necessário que ele organize o conteúdo e atividades em uma Sequência Didática (SD), ferramenta que organiza conteúdos e atividades relacionadas com os objetivos das aulas, auxiliando no desenvolvimento de competências e habilidades dos alunos. Como metodologia de pesquisa utilizou-se a pesquisa qualitativa, pois analisa atitudes, motivações e comportamentos dos alunos. Para responder à pergunta: Quais as fontes de energia que poderiam ser utilizadas para gerar energia elétrica em uma cidade onde não existem hidroelétricas. Utilizou-se a ABP para o trabalho com os alunos, que foram divididos em grupo. Ao analisar os relatórios, a apresentação dos grupos, e defesa de resultados de cada um deles, percebe-se nos alunos um amadurecimento pois foram capazes de trabalhar em grupo, analisar e refletir frente aos resultados obtidos, além de mostrar que eles são capazes de utilizar ferramentas como internet, powerpoint e redigir relatórios bem estruturados.
\end{abstract}

Palavras-chave: Ensino de Física; Sequência Didática; Aprendizagem Baseada em Problemas

\section{ABSTRACT/ RESUMEN}

Generally, the teaching-learning process is inefficient when the methodology used by the teacher is not very stimulating, which is why the high school student is little motivated to study Physics. To change this scenario, there are currently methodological approaches that place the student at the center of the teaching process, being the protagonist of his own learning. One of these methodologies, used in this research, is called Problem Based Learning (PBL), which consists of presenting a problem situation, which leads students to an analysis, reflection and pointing out solutions for solve it, in all its aspects. The teacher acts as an advisor of the process, being necessary that he organizes the content and activities in a Didactic Sequence (SD), a tool that organizes contents

\footnotetext{
${ }^{1}$ Doutora em Física, Universidade Estadual de Campinas (UNICAMP). Professora do departamento de Física, Faculdade de Ciências e Tecnologia (FCT) da Universidade Estadual Paulista "Júlio de Mesquita Filho" (UNESP), Presidente Prudente, São Paulo, Brasil. Endereço para correspondência: Rua Roberto Simonsen, 305, Centro Educacional, Presidente Prudente, São Paulo, Brasil, CEP: 19060900. ORCID iD https://orcid.org/0000-00023727-2574. E-mail: amo.araya@ unesp.br.

${ }^{2}$ Mestre em Ensino de Física, Universidade Estadual Paulista "Júlio de Mesquita Filho" (UNESP). Professor de Física do Ensino Médio e Matemática do Ensino Fundamental no Serviço Social da Indústria (SESI), Santo Anastácio, São Paulo, Brasil. Endereço para correspondência: Rua Roberto Simonsen, 305, Centro Educacional, Presidente Prudente, São Paulo, Brasil, CEP: 19060900. ORCID iD: https://orcid.org/0000-0001-7399-4796. Email: rodrigo.lacasa@gmail.com.
} 
and activities related to the objectives of the classes, helping in the development of competences and skills of the students. As a research methodology was used qualitative research because it analyzes students' attitudes, motivations and behaviors. To answer the question: What are the sources of energy that could be used to generate electricity in a city where there are no hydroelectric plants? PBL was used to work with students, who were divided into groups. When analyzing the reports, the presentation of the groups, and the defense of the results of each one, it is noticed in the students a maturity because they were able to work in groups, analyze and reflect on the results obtained, in addition to showing that they are capable of use tools such as internet, powerpoint and write wellstructured reports.

Keywords: Physics teaching; Didatic Sequence; Problem-Based Learning.

\section{INTRODUÇÃO}

Frente aos novos paradigmas deve-se considerar que nos últimos anos tem se desenvolvido metodologias específicas para promover a aprendizagem ativa e que tem se logrado resultados positivos e significativos na aprendizagem dos estudantes, quando comparados com os alcançados por meio de métodos tradicionais centrados no professor e nos conteúdos (REDISH, 2003).

Neste cenário, as pesquisas atuais na área de didática analisam e desenvolvem metodologias de aprendizagem nas quais os alunos participam efetivamente das atividades em classe e fora dela, levando-os a refletir sobre os conteúdos e sua significância, com orientação do professor.

No Ensino Médio - especificamente no ensino de Física - a situação não é diferente. Temos o agravante de que a "propaganda" que circula entre os alunos sobre as aulas de Física é desalentadora, então as propostas de metodologias que "invertam esta situação" são bemvindas.

Nos últimos 20 anos, principalmente, tem se desenvolvido metodologias que promovem a aprendizagem significativa, chamadas "metodologias ativas", que têm tido sucesso quando comparadas com os métodos convencionais centrados no professor e no conteúdo (DENZIN, 1989).

Segundo colocado por Mitre et al (2008), além da sala de aula, como concebida atualmente, existe uma sociedade em mudança contínua onde os conceitos de espaço-tempo e sociedade mudaram radicalmente. Isto implica em mudanças para um novo ensino que prepare sujeitos que desenvolvam a autonomia individual em íntima relação com o conceito de coletivo. Como indicado por Mitre et al. (2008, p.2134),

A educação deve ser capaz de desencadear uma visão do todo — de interdependência e de transdisciplinaridade - além de possibilitar a construção de redes de mudanças sociais, com a consequente expansão da consciência individual e coletiva. 
Quando se faz uma leitura das pesquisas sobre o atual estado do ensino de Física e das perspectivas que as "Metodologias Ativas" nos trazem, parece fácil de implementar, até que tentamos colocar no papel todas as mudanças na postura do professor, do aluno e na sala de aula. É um grande desafio para professores em exercício e futuros professores, mas a educação em si é um desafio e é necessário entender que como a sociedade muda, o ensino especificamente o ensino de física - tem que acompanhar estas mudanças.

\section{Objetivos:}

Desenvolver uma sequência didática sobre o ensino-aprendizagem do conteúdo geração de energia elétrica utilizando a metodologia ABP;

Promover o desenvolvimento de habilidades colaborativas nos alunos na realização de atividades intra e extraclasse.

\section{BASE TEÓRICA}

Uma solução que se apresenta para promover uma aprendizagem significativa é utilizar metodologias que envolvam os alunos na aquisição do conhecimento; as metodologias ativas. Trata-se de um processo em que os estudantes realizam atividades (resolução de problemas, análise de textos, atividades práticas etc.) que promovem a análise, síntese e avaliação.

As metodologias ativas mais conhecidas para uma aprendizagem significativa, centradas nos estudantes, são: Aprendizagem Baseada em Problemas, Aprendizagem Colaborativa e Cooperativa, Instrução por pares e Aprendizagem por Projetos.

No trabalho de Souza e Dourado (2015) é apresentado um breve levantamento bibliográfico destas metodologias inovadoras e, para promover estratégias ativas de aprendizagem, é necessário propor atividades que, segundo Sánchez-Rodríguez, Ruiz-Palmero e Sánchez (2014, p.3, tradução nossa) devem:

[...] utilizar o tempo fora da sala de aula para realizar atividades de aprendizagem que tradicionalmente são realizadas dentro da sala de aula, enquanto isso, na sala de aula, com a experiência do professor e orientação, o tempo é gasto em promover e facilitar outros processos e aquisição de conhecimento prático.

Uma metodologia com foco na aprendizagem, pesquisa e reflexão, onde o professor propõe um problema para os alunos chegar a una possível solução, é a chamada Aprendizagem Baseada em Problemas (ABP). Barrows (1986) define a ABP como um método de aprendizagem baseado no princípio de usar problemas como ponto de partida para a aquisição 
e integração de novos conhecimentos. Nesta metodologia, os protagonistas da aprendizagem são os próprios alunos, que assumem a responsabilidade de serem uma parte ativa no processo

Pensando em contribuir com o ensino de física fica a pergunta: "Como utilizar a ABP no ensino da física para desenvolver a aprendizagem de um conteúdo significativo para os alunos". Em resposta a esta pergunta escolhemos o tema "Geração de Energia Elétrica", devido a aspectos sociais e ambientais envolvidos neste tópico. O tema faz parte do currículo do estado de São Paulo para o terceiro ano do Ensino Médio.

Neste trabalho utilizamos a Aprendizagem Baseada em Problemas (ABP), que de acordo com Leite e Afonso (2001) e Leite e Esteves (2005), a estrutura básica desta metodologia ocorre em quatro etapas: a primeira inicia com a escolha do contexto real da vida dos alunos para a identificação do problema e a preparação e sistematização, pelo professor, dos materiais necessários à investigação.

A segunda etapa segue com os alunos recebendo do professor o contexto problemático. Eles iniciam o processo de elaboração das questões-problema acerca do contexto de que eles têm conhecimento prévio e que aprofundarão. Em seguida, passa-se à discussão dessas questões em grupo (acompanhados pelo professor tutor) para, a partir daí iniciar o planejamento da investigação para a resolução dos problemas.

A terceira etapa é o processo de desenvolvimento da investigação por meio dos diversos recursos disponibilizados pelo professor tutor. Os alunos, nesta fase, apropriam-se das informações por meio de leitura e análise crítica, pesquisam na internet, discutem em grupo o material coletado e levantam as hipóteses de solução.

Na última etapa, elaboram a síntese das discussões e reflexões, sistematizam as soluções encontradas para os problemas, preparam a apresentação para a turma e para o tutor e promovem a autoavaliação do processo de aprendizagem que realizaram.

Tratando-se da ABP, para Hmelo-Silver (2004), o aluno aprende por meio da experiência de resolver problemas que não tem uma única resposta correta. Os alunos trabalham em grupos colaborativos para identificarem o que eles precisam saber para resolver um determinado problema. As evidências sugerem que a ABP é uma abordagem de ensino que dispõe de um grande potencial para ajudar os alunos a desenvolverem uma compreensão flexível e algumas habilidades de aprendizagem que estarão presentes ao longo da vida.

O uso da metodologia foi escolhido porque é uma forma eficaz de aproveitar quase ao máximo todo o potencial de conhecimento que o tipo de conteúdo escolhido possui. É possível 
que este tema, assim como muitos outros da Física e Ciências em geral, seja explorado em vários âmbitos (que não seja só no científico), seja social, econômico, geográfico, ambiental, político, entre outras ópticas sobre o mesmo tema.

A riqueza que um debate acerca das ópticas de diferentes áreas do conhecimento poderia proporcionar a um ambiente de sala de aula, é alcançada com a ABP, por permitir toda essa transdisciplinaridade sem a necessidade da identificação de momentos onde uma área atua mais que a outra, fazendo com que o tópico seja realmente trabalhado de forma universal. Em outras palavras a aula deixa de ser de Física e se torna algo global, que envolve todas as outras áreas sem a necessidade de ser chamada de "aula de matemática", ou "aula de Geografia", o que acaba com a individualidade ou divisibilidade do conhecimento.

\section{Sequência didática}

Uma Sequência Didática (SD) é composta por várias atividades encadeadas de questionamentos, atitudes, procedimentos e ações que os alunos executam com a mediação do professor. As atividades que fazem parte da SD são ordenadas de maneira a aprofundar o tema que está sendo estudado e são variadas em termos de estratégia: leituras, aula dialogada, simulações computacionais, experimentos etc. (MANTOVANI; ARAYA, 2015).

De acordo com os estudos de Zabala (1998), as SD do modelo tradicional constam as seguintes fases:

a) Atividade motivadora relacionada com uma situação conflitante da realidade experimental dos alunos.

b) Explicação das perguntas ou problemas que esta situação coloca.

c) Respostas intuitivas ou "hipóteses".

d) Seleção e esboço das fontes de informação e planejamento da investigação.

e) Coleta, seleção e classificação dos dados.

f) Generalização das conclusões tiradas.

g) Expressão e comunicação.

Também há indicativos da estrutura bem definida da SD em Delizoicov e Angotti (1990). Os autores destacam três momentos pedagógicos e são eles: Problematização do tema, Organização do conhecimento e Aplicação do conhecimento. Os autores também, lembram que a avaliação é realizada processualmente, tendo um momento ao final para reflexões e reavaliação da metodologia. 
Um forte indicativo para os professores utilizarem SD na organização de atividades e conteúdo que permitam o desenvolvimento de diferentes habilidades, se encontra nas diretrizes curriculares do Ministério de Educação (BRASIL, 2012). O documento destaca que as SD contribuem com a consolidação de conhecimentos sendo uma ferramenta muito importante para a construção do conhecimento:

Ao organizar a sequência didática, o professor poderá incluir atividades diversas como leitura, pesquisa individual ou coletiva, aula dialogada, produções textuais, aulas práticas, etc., pois a sequência de atividades visa trabalhar um conteúdo específico, um tema ou um gênero textual da exploração inicial até a formação de um conceito, uma ideia, uma elaboração prática, uma produção escrita (BRASIL, 2012, p.21).

\section{PROCEDIMENTOS METODOLÓGICOS}

Para o desenvolvimento das atividades é utilizada, como ferramenta, a Sequência Didática (SD). As sequências didáticas (SD) contribuem com a consolidação de conhecimentos que estão em fase de construção e permitem que, progressivamente, novas aquisições sejam possíveis, pois a organização dessas atividades prevê uma progressão modular, a partir do levantamento dos conhecimentos que os alunos já possuem sobre um determinado assunto, conforme Brasil (2012, p. 20):

Ao organizar a sequência didática, o professor poderá incluir atividades diversas como leitura, pesquisa individual ou coletiva, aula dialogada, produções textuais, aulas práticas, etc., pois a sequência de atividades visa trabalhar um conteúdo específico, um tema ou um gênero textual da exploração inicial até a formação de um conceito, uma ideia, uma elaboração prática, uma produção escrita

A pesquisa foi realizada em uma escola particular de Santo Anastácio, interior do estado de São Paulo, com um total de 18 alunos, todos alunos do terceiro ano do Ensino Médio. O conteúdo é abordado no terceiro bimestre do terceiro ano, na rede escolar de ensino (no estudo dos fenômenos magnéticos e leis do eletromagnetismo), faz parte do currículo do estado de São Paulo e as atividades desenvolvidas apresentadas podem servir de apoio a qualquer professor que lecione a disciplina de Física na rede estadual de ensino.

Foi dado o tempo de quatro semanas para realização da pesquisa. Os alunos tinham quatro aulas semanais de Física, porém não podiam usufruir de uma sala de informática já que a escola não possuía. O professor utilizou sempre um tempo inicial de cada aula para acompanhar o desenvolvimento da pesquisa destes alunos que levavam sempre várias anotações sobre o que já haviam feito fora da sala de aula e, também, sobre os debates que realizavam entre si. 


\section{Características da pesquisa}

As características da metodologia adotada, no desenvolvimento da pesquisa, a apontam como uma pesquisa qualitativa, pois se preocupa com o levantamento dos dados durante todo o processo, o que permite compreender e interpretar comportamentos, opiniões e expectativas do grupo (RICHARDSON, 2011).

Pesquisadores do tema apontam características importantes que definem uma pesquisa qualitativa, como, por exemplo:

- A característica principal é entender o processo e não obter dados quantitativos;

- Os dados podem ser obtidos de várias formas, como grupos de reflexão, entrevistas individuais, análise de comportamentos;

- Entender as motivações que levam a desenvolver as atividades e levantar hipóteses;

- É o método mais utilizado se você não tiver dados ou hipóteses que possam ser levantadas.

Frente a esta características podemos dizer que é necessário, também, uma abordagem exploratória, pois no início faltam informações para compreender o problema e chegar a uma hipótese, sendo esta uma caraterística desta abordagem que auxilia no levantamento de informações e não dados estatísticos. Neste tipo de pesquisa podem ser utilizadas entrevistas semiestruturadas, entrevistas por telefone e coleta de dados que permitam aprofundar conhecimentos. Richardson (2011, p.80) descreve as potencialidades da pesquisa qualitativa,

Os estudos que empregam uma metodologia qualitativa podem descrever a complexidade de determinado problema, analisar a interação de certas variáveis, compreender e classificar processos dinâmicos vividos por grupos sociais, contribuir no processo de mudança de determinado grupo e possibilitar, em maior nível de profundidade, o entendimento das particularidades do comportamento dos indivíduos.

Acreditamos que esta metodologia é mais apropriada para analisar as atividades na qual professor-aluno e aluno-aluno devem estar sempre em contato com o problema e apresentar possíveis soluções que envolvem a Física, o contexto e as consequências sociais, como proposto pela ABP.

A proposta de trabalho utilizando a $\mathrm{ABP}$ tem como objetivo de trazer para o aluno uma metodologia diferente à forma tradicional de ensinar, pois como indicado no texto de HmeloSilver (2004, p.235, tradução nossa), “[...] o aluno aprende através da experiência de resolver 
problemas que não tem uma única resposta correta". Se propôs a seguinte situação problema aos alunos:

Você é o responsável pelo setor de pesquisa e implementação de tecnologia em uma empresa que está realizando uma pesquisa para encontrar uma forma de gerar e distribuir energia elétrica em uma região onde não existem rios próximos, nem muitos ventos e a quantidade de luz solar durante o ano é baixa. Você precisa procurar por uma forma de energia que possa abastecer a esta região sem depender da produção de energia de alguma outra região próxima, que poderia vender energia para sua empresa.

Este problema proposto foi o ponto inicial da SD, sendo referência para o desenvolvimento de todas as atividades. A SD utilizada pelo professor tem as características evidenciadas no Quadro 1 (OLIVEIRA, 2019).

Quadro 1 - Características da sequência didática

\begin{tabular}{|c|c|c|c|c|}
\hline Momento & Aula Objetivo & Atividade & $\begin{array}{c}\text { Habilidade a ser } \\
\text { desenvolvida }\end{array}$ & Tempo \\
\hline $\begin{array}{c}\text { A SD consta } \\
\text { de } \\
\text { momentos }\end{array}$ & $\begin{array}{c}\text { Cada momento } \\
\text { consta de uma ou } \\
\text { mais aulas com } \\
\text { objetivo específico. }\end{array}$ & $\begin{array}{c}\text { O professor } \\
\text { define a atividade } \\
\text { da aula segundo o } \\
\text { objetivo }\end{array}$ & $\begin{array}{c}\text { A atividade definida } \\
\text { deve aprimorar a } \\
\text { habilidade }\end{array}$ & $\begin{array}{c}\text { Se define } \\
\text { o tempo de } \\
\text { duração da } \\
\text { aula. }\end{array}$ \\
\hline
\end{tabular}

Fonte: Adaptado de Oliveira (2019, p.45)

Após o desenvolvimento das atividades organizadas na SD, os alunos redigiram um relatório. Neste, consta todo o processo do trabalho que o grupo realizou, desde as escolhas iniciais (levantamentos dos dados sobre os tipos de distribuição de energia elétrica disponíveis) até os argumentos que justificassem as escolhas, chegando ao ponto em que mostraram o porquê da forma final escolhida.

Após a correção dos relatórios ainda houve a apresentação de todos os grupos. Foi surpreendente a forma como apresentaram, devido à complexidade dos discursos e pelo debate gerado - ficou evidente que todos os membros do grupo participaram ativamente da pesquisa, pois todos falaram sobre os seus respectivos aspectos na hora de justificarem seus argumentos a favor da escolha final. Estes alunos levavam sempre várias anotações sobre o que já haviam feito e sobre os debates que realizavam entre si.

Foi necessário um trabalho colaborativo e participação do debate, pois cada grupo (composto por quatro integrantes) teve que se dividir para que cada um fosse responsável por uma óptica diferente de análise do problema em questão: um que se responsabilizasse pelo aspecto geográfico, outro pelo científico, outro pelo ecológico e outro pelo financeiro. Isso fez 
com que os alunos realizassem parte da pesquisa de forma individual, para depois analisar os dados de forma colaborativa.

\section{RESULTADOS}

Desde o início os alunos entenderam que o objetivo deles era convencer quem os estivesse assistindo de que suas escolhas foram as melhores e mais funcionais, levando em conta todos aqueles aspectos mencionados anteriormente, como se estivessem vendendo um produto. Essa proposta fez com que os alunos encarassem o problema de forma séria, respeitando os limites dos outros aspectos da pesquisa, mas sem deixar de insistirem em propostas que fossem mais adequadas em relação à sua óptica individual de análise do problema (geográfica, ecológica, financeira ou científica).

Como dito anteriormente não foi apenas uma pesquisa formal, onde o objetivo seria apenas chegar a uma resposta. Foi um trabalho colaborativo, no qual todos os indivíduos participaram de maneira ativa para responder a uma questão que no início se apresentou como simples, mas que se mostrou complexa conforme os alunos pesquisavam e se aprofundavam nos dados encontrados.

Surgiu um comentário, quando os alunos foram perguntados sobre como era ter uma aula desta forma - onde eles iniciavam a aula, em que o aluno disse que "tentou colocar o texto da proposta inicial do professor no site do Google e não apareceu resultado nenhum”. O aluno completou dizendo que neste ponto já tinha desanimado de fazer a pesquisa, pois todas as outras que já estava acostumado a fazer eram fáceis. Achou que apenas era necessário encontrar um bom texto da internet, o resumir e entregar ao professor. Os alunos disseram que esta forma de pesquisa os ajudou muito a entenderem sobre o conceito de Geração e Distribuição de Energia Elétrica e os fizeram pensar de forma reflexiva a respeito do tema. A seguir, em quadros, será apresentada uma análise de cada momento da SD aplicada, assim, no Quadro 2 temos os dados do primer contato dos alunos com a proposta e organização dos grupos. 
Quadro 2 - Momento 1.1 da SD

\begin{tabular}{|c|c|c|c|}
\hline Aula - Objetivo & Atividade & $\begin{array}{c}\text { Habilidade a ser } \\
\text { desenvolvida }\end{array}$ & Tempo \\
\hline $\begin{array}{c}\text { Apresentar a } \\
\text { proposta ABP e } \\
\text { explicar o } \\
\text { problema em } \\
\text { questão aos alunos. }\end{array}$ & $\begin{array}{c}\text { Se faz a separação dos alunos e } \\
\text { eles delegam as funções para cada } \\
\text { integrante, designando quem } \\
\text { ficará responsável pelos aspectos } \\
\text { ambiental, geográfico, tecnológico } \\
\text { e financeiro. }\end{array}$ & $\begin{array}{c}\text { Análise de pessoas e de } \\
\text { virtudes; elencar as } \\
\text { individualidades de cada aluno } \\
\text { para que se encaixem em um } \\
\text { único aspecto. }\end{array}$ & 20min \\
\hline
\end{tabular}

Fonte: Elaboração pelos autores

O próximo passo do professor foi escrever na lousa a proposta (disparadora da ABP), sobre a geração de energia elétrica. O professor então leu com os alunos a proposta e explicou que isso seria feito pelos alunos, mas que o professor não iria "começar a aula explicando" da forma como eles estavam acostumados; a aula se iniciaria com esta pesquisa.

Feito isso, a sala se dividiu em quatro grupos (dois com cinco integrantes e outros dois com quatro integrantes). Após isso, explicou o que - essencialmente - eles deveriam fazer neste trabalho (devido ao fato de que não teria como o professor prever o que eles entregariam como resultado deste trabalho, já que o mesmo dá abertura a muitos resultados possíveis de várias formas diferentes). A continuação, seguindo a proposta apresentada, ressalou-se que cada integrante do grupo deveria defender - a todo o momento - o seu ponto de vista baseado na área a qual lhe foi atribuída (pontos de vista Ecológico, Financeiro, Científico e Geográfico, respectivamente). Vale ressaltar que esta escolha de qual área cada um iria ser responsável foi de escolha dos próprios integrantes dos grupos. A continuação, os alunos realizaram a pesquisa segundo consta no Quadro 3.

Quadro 3 - Momento 1.2 da SD

\begin{tabular}{|c|c|c|c|}
\hline Aula - Objetivo & Atividade & Habilidade a ser desenvolvida & Tempo \\
\hline $\begin{array}{c}\text { Auxiliar os alunos } \\
\text { na pesquisa inicial } \\
\text { (levantamento de } \\
\text { dados sobre usinas } \\
\text { no mundo). }\end{array}$ & $\begin{array}{c}\text { Pesquisar na internet } \\
\text { sobre a utilização de } \\
\text { usinas de geração de } \\
\text { energia elétrica no } \\
\text { mundo todo; }\end{array}$ & $\begin{array}{c}\text { Utilizar adequadamente } \\
\text { fontes de pesquisa como } \\
\text { bibliotecas, enciclopédias e } \\
\text { internet; }\end{array}$ & $\begin{array}{c}\text { Fora de } \\
\text { sala de } \\
\text { aula/ }\end{array}$ \\
$\begin{array}{c}\text { Relatar os dados } \\
\text { encontrados na pesquisa } \\
\text { para futura discussão. }\end{array}$ & $\begin{array}{c}\text { Ler e interpretar gráficos que } \\
\text { representam as formas de gerar } \\
\text { energia elétrica mais utilizadas } \\
\text { no mundo todo. }\end{array}$ & 30min. \\
\hline
\end{tabular}

Fonte: Elaboração pelos autores 
Partindo das atividades realizadas no momento 1, e como consta dos quadros 1 e 2 , eles fizeram o planejamento do trabalho, como se fossem realmente uma empresa. Os grupos se organizaram basicamente com o seguinte roteiro de trabalho:

- Atribuir a cada integrante do grupo um aspecto diferente (financeiro, geográfico, ecológico ou científico), de forma livre em cada grupo;

- Fazer um levantamento inicial sobre as formas de gerar e distribuir energia elétrica mais utilizadas no mundo;

- Relatar as informações encontradas nessa pesquisa inicial, com a finalidade de préselecionarem as formas que fossem possíveis de serem implementadas com as limitações impostas pela proposta inicial;

- A partir das pré-selecionadas, individualmente eleger, no grupo, aquela que melhor atende ao aspecto de análise de cada integrante (o aluno do setor ecológico irá escolher a melhor possível do ponto de vista ecológico, por exemplo);

Até o fim do momento 1 os alunos criaram o plano mencionado anteriormente e fizeram o levantamento inicial das formas mais utilizadas no mundo, relatando os dados encontrados no grupo e debatendo os dados, como indicado no quadro 2.

No momento 2 da SD, quadro 3, os alunos pré-selecionaram as formas que seriam possíveis de serem utilizadas com base nas limitações apresentadas na proposta inicial (apresentada como sendo o problema disparador deste trabalho, sobre a geração de energia para uma cidade). Essa parte foi feita em grupo, depois de, individualmente e em suas casas, os alunos fazerem a pesquisa do levantamento inicial. A parte na escola (que foi em grupo) foi feita em aproximadamente em 30min, economizando tempo de pesquisa. Os alunos foram orientados a sempre escreverem os pontos positivos e negativos de seus respectivos aspectos sob as formas já pré-selecionadas, para que todas as decisões sejam justificadas. Nesta etapa, a análise promoveu nos alunos um desenvolvimento de habilidades de tomada de decisão, percebendo que não há apenas uma escolha correta e perfeita, mas que é necessária análise para tomar decisões da melhor forma possível, respeitando os diferentes olhares sobre um mesmo problema. No Quadro 4 se encontra um detalhe das atividades. 
Quadro 4 - Momento 2.1 da SD

\begin{tabular}{|c|c|c|c|}
\hline Aula - Objetivo & Atividade & $\begin{array}{c}\text { Habilidade a ser } \\
\text { desenvolvida }\end{array}$ & Tempo \\
\hline $\begin{array}{c}\text { Debater e escolher a } \\
\text { melhor forma, } \\
\text { equilibrando os quatro } \\
\text { aspectos da escolha. }\end{array}$ & $\begin{array}{c}\text { Individualmente os alunos } \\
\text { escolhem uma ou duas formas que } \\
\text { melhor se encaixam com o seu } \\
\text { ponto de vista (aspecto de } \\
\text { análise); }\end{array}$ & $\begin{array}{c}\text { Debate a resolução de } \\
\text { problemas; }\end{array}$ & $\begin{array}{c}\text { Fora de } \\
\text { sala de } \\
\text { aula e } \\
\text { selecionadas individualmente e } \\
\text { elegerem uma única que } \\
\text { represente os interesses do grupo. }\end{array}$ \\
$\begin{array}{c}\text { Capacidade de resolver } \\
\text { problemas em grupo } \\
\text { mesmo na presença de } \\
\text { ideias divergentes. }\end{array}$ & $\begin{array}{c}\text { 30min. } \\
\text { em sala }\end{array}$ \\
\hline
\end{tabular}

Fonte: Elaboração pelos autores

Houve certa divergência de ideias para que na escolha final se mantivesse um equilíbrio entre os pontos positivos e negativos de cada análise individual. Porém esta divergência foi enriquecedora para a atividade, já que os alunos confrontaram suas ideias e perceberam que há a impossibilidade de perfeição na resolução de problemas reais, nos quais se faz necessárias discussões que amenizem os pontos negativos de uma decisão final que fosse satisfatória à resolução do problema proposto. Após a apresentação dos dados individuais ao grupo, da escolha final e do debate das formas selecionadas de interesse do grupo, Quadro 5, se passa a etapa final.

De forma resumida as atividades realizadas no momento 2 e 3, Quadros 5 e 6, foram

- Em grupo, cada integrante apresentará sua proposta individual pautada em argumentos que justifiquem suas escolhas individuais;

- Debater e escolher, com base nos argumentos apresentados, qual a forma de gerar energia elétrica que mais equilibra pontos positivos e negativos nestes quatro aspectos;

- Fazer uma apresentação da escolha do grupo, em slide, e entregar um relatório que mostra esse processo de trabalho completo.

Quadro 5 - Momento 2. da SD

\begin{tabular}{|c|c|c|c|}
\hline Aula - Objetivo & Atividade & $\begin{array}{c}\text { Habilidade a ser } \\
\text { desenvolvida }\end{array}$ & Tempo \\
\hline $\begin{array}{c}\text { Debater e escolher a } \\
\text { melhor forma, } \\
\text { equilibrando os quatro } \\
\text { aspectos da escolha. }\end{array}$ & $\begin{array}{c}\text { Debate final das formas } \\
\text { selecionadas individualmente e } \\
\text { escolha de uma única que } \\
\text { represente os interesses do grupo. } \\
\text { Se redige o texto final }\end{array}$ & $\begin{array}{c}\text { Leitura reflexiva, } \\
\text { Desenvolver a capacidade } \\
\text { de escutar o grupo mesmo } \\
\text { na presença de ideias } \\
\text { divergentes. }\end{array}$ & $\begin{array}{c}30 \mathrm{~min} . \\
\text { em sala }\end{array}$ \\
\hline
\end{tabular}

Fonte: Elaboração pelos autores 
$\mathrm{Na}$ atividade final os grupos chegaram na aula com seus relatórios e as apresentações em slides prontas. Este foi o único momento em toda a sequência didática no qual uma aula inteira foi utilizada somente para o trabalho proposto. Entretanto, devido ao debate realizado no final, o tempo previsto foi curto para que a atividade toda fosse completada, que se estendeu por duas aulas (1h e 40min). Os grupos, com o tempo de 10min, apresentaram suas escolhas finais e exibiram as justificativas de cada tomada de decisão, utilizando um projetor de multimídia como ferramenta, como mostrado no Quadro 6 (salientando a desnecessidade de um laboratório de informática para desenvolvimento do trabalho).

Quadro 6 - Momento 3 da SD

\begin{tabular}{|c|c|c|c|}
\hline $\begin{array}{c}\text { Aula }- \\
\text { Objetivo }\end{array}$ & Atividade & $\begin{array}{c}\text { Habilidade a ser } \\
\text { desenvolvida }\end{array}$ & Tempo \\
\hline $\begin{array}{c}\text { Apresentar a } \\
\text { solução de } \\
\text { cada grupo. }\end{array}$ & $\begin{array}{c}\text { Apresentar com uso de slides os } \\
\text { resultados da pesquisa e todo o processo } \\
\text { para chegar até a escolha final, } \\
\text { mostrando os pontos positivos e } \\
\text { negativos sob a ótica de cada aspecto. }\end{array}$ & $\begin{array}{c}\text { Elaborar comunicação } \\
\text { escrita ou oral para relatar } \\
\text { resultados. Utilizar } \\
\text { linguagem científica }\end{array}$ & 50min \\
adequada. & \\
\hline
\end{tabular}

Fonte: Elaboração pelos autores

Cada integrante teve a obrigação de fazer parte ativa da apresentação, pois cada um teve papel diferenciado no trabalho e que não pôde ser coberto por outro integrante. Fez-se necessário então que cada membro falasse sobre seu aspecto de análise para que as escolhas fossem devidamente justificadas. Também, ao final das apresentações, os alunos deveriam entregar os relatórios escritos ao professor, que serviu de objeto de avaliação parcial do trabalho realizado pelos alunos. Como apresentado no Quadro 7, o professor fez o fechamento com um debate sobre as soluções apresentadas pelos grupos.

Nesta etapa e finalizando a SD, o professor mediou o debate (que se iniciou no momento 3 e se encerrou no momento 4), no qual foram confrontadas as ideias finais de cada grupo. $\mathrm{O}$ professor também fez o fechamento, fazendo uma fala final sobre o conceito de geração de energia elétrica e distribuição, formalizando algumas ideias que não ficaram bem definidas pelos estudantes, concluindo o trabalho como apresentado no Quadro 7.

Quadro 7 - Momento 4 da SD

\begin{tabular}{|c|c|c|}
\hline Aula - Objetivo & Atividade & Tempo \\
\hline Fechamento & $\begin{array}{c}\text { O professor faz a mediação em um debate com os outros } \\
\text { grupos, a fim de discutir sobre as soluções encontradas. }\end{array}$ & 20min \\
\hline
\end{tabular}

Fonte: Elaboração pelos autores 
Ao final das etapas os alunos chegaram às seguintes soluções para o problema proposto no Quadro 8:

Quadro 8 - Soluções apresentadas pelos grupos

\begin{tabular}{|c|c|}
\hline Grupo A & Biogás \\
\hline Grupo B & Usina Nuclear \\
\hline Grupo C & Biomassa \\
\hline Grupo D & Usina Nuclear \\
\hline
\end{tabular}

Fonte: Elaboração pelos autores

A partir da aplicação desta proposta, que incluiu a avaliação do desenvolvimento de competências colaborativas dos estudantes, foi possível caracterizar o processo de construção de conhecimento, analisando intervenções e processos de estudo que ocorreram na sala de aula, sendo eles o relatório produzido pelos alunos (que constou todo o processo de análise e escolha das diferentes opções que os alunos puderam escolher) e a apresentação em slides feita nos últimos momentos de aplicação da S.D.

\section{CONSIDERAÇÕES FINAIS}

Com a metodologia ABP foi possível resolver um problema que é comum nas aulas de Física - a falta de tempo. O trabalho pôde, sem a necessidade de muito tempo em sala de aula, ser concluído com êxito, em todas as suas etapas, devido ao uso dos minutos iniciais apenas das aulas e das atividades extraclasse, sem falar que os alunos foram levados a refletir sobre o uso da internet na obtenção do conhecimento.

Foi possível também constatar que, mesmo sem um laboratório de informática (o qual a escola não possuía), foi possível realizar atividades com metodologias não tradicionais que envolvem a pesquisa, reflexão, trabalho colaborativo entre alunos e análise de situação problema, ultrapassando os limites que eram impostos em trabalhos de "pesquisa" nos quais o aluno usa apenas o "copiar e colar".

Os alunos conseguiram enxergar em si mesmos a capacidade de fazer algo além do que eles estavam acostumados a fazer (que era apenas pesquisar textos na internet e resumi-los, sem ter que desenvolver a habilidade da tomada de decisão, da análise e do debate, ao mesmo tempo). Eles perceberam também que não seria possível obter uma "resposta certa", pois não existe solução ideal no mundo real, já que as condições "reais" levam em conta todas as variáveis possíveis, e que uma empresa trabalha de acordo com vantagens e desvantagens de 
recursos disponíveis. Isso promoveu, claramente, a habilidade de análise crítica de um problema, levando em conta todos os aspectos possíveis.

Ficou perceptível, por parte dos alunos, que o tema "geração de energia elétrica" é mais complexo do que imaginavam - com falas do tipo:

Fala de aluno do $3^{\circ}$ ano: Eu pensava que era apenas colocar que alguma coisa movimentava um motor e este gerava energia, que a única coisa que mudava era o que girava, mas vai muito além disso!

Fala de aluno do $3^{\circ}$ ano: Não tem como não levar em conta o mal que pode ser feito ao meio ambiente e os custos para gerar cada tipo.

Também houve falas que confirmam a validade desta metodologia no ensino de Ciências, como por exemplo:

Fala de aluno do $3^{\circ}$ ano: Difícil chegar a um acordo com a galera, mas legal chegar ao fim.

Fala de aluno do $3^{\circ}$ ano: Me senti importante, eles gostaram das minhas falas, gostei das aulas

Além da aprendizagem contextualizada do tema houve também a promoção do debate, que fez com que as ideias fossem confrontadas quase que a todo momento. Todos participaram (o professor teve que intervir apenas para mediar as locuções e fechar o debate, fora isso houve participação de quase todos os envolvidos), sempre defendendo de forma única o seu ponto de vista. Isso deixou bem claro que a proposta atingiu seu objetivo de fazer com que os alunos conseguissem analisar uma situação de vários pontos de vista diferentes e aprendessem a argumentar sobre seu ponto de vista, levando em conta vários fatores.

Os alunos responsáveis por aspectos diferentes da pesquisa conseguiram fazer a separação das formas de visualizar o mesmo problema, destacando o seu papel em relação aos demais.

Pode-se então concluir que a SD construída e proposta neste trabalho com $\mathrm{ABP}$, pode ser considerada válida para sua utilização em uma aula de Física deste tema e outros da física. Vale ressaltar a necessidade de ajustes para cada tipo de sala de aula, com diferentes contextos, com diferentes alunos, de acordo com o olhar do professor aplicador sob seu ambiente escolar. Além disso também é possível utilizar esta metodologia de ABP em outras propostas com outros conteúdos, desde que sejam considerados todos os fatores que foram apresentados aqui (estrutura escolar, tempo, habilidades desejadas a serem desenvolvidas pelos alunos após a aplicação da SD, conhecimento do tema por parte do professor e apoio dos dirigentes escolares).

Seria importante que os professores tivessem formação continuada no tema Metodologias Ativas para que nas aulas fossem utilizadas em diferentes oportunidades. 


\section{REFERÊNCIAS}

BARROWS, H. S. A. Taxonomy of Problem-Based Learning methods. Medical Education, [S.I.], v.20, n.6, p. 481-486, nov. 1986.

BRASIL, Secretaria de Educação Básica. Diretoria de Apoio à Gestão Educacional. Pacto nacional pela alfabetização na idade certa: alfabetização em foco: projetos didáticos e sequências didáticas em diálogo com os diferentes componentes curriculares: ano 03, unidade 06 / Ministério da Educação, Secretaria de Educação Básica, Diretoria de Apoio à Gestão Educacional. Brasília: MEC, SEB, 2012. p. 47.

DELIZOICOV, D.; ANGOTTI, J. A. P. Metodologia do Ensino de Ciências. São Paulo, 1. ed. Cortez, 1990. 368 p.

DENZIN, N. K. The Research Act: A theoretical introduction to Sociological Methods. 3.ed. Englewood Cliffs, NJ: Prentice-Hall, 1989.

HMELO-SILVER, C. E. Problem-Based Learning: What and How Do students Learn?. Educational Psychology Review, v.16, n.3, p. 235-266, set. 2004.

LEITE, L; AFONSO, A. S. Aprendizagem baseada na resolução de problemas: Características, organização e supervisão. In: XIV CONGRESO DE ENSINANTES DE CIENCIAS DE GALICIA, 48., 2001, Santiago de Compostela. Anais [...]. Santiago de Compostela: ENCIGA, 2001. p. 253-259.

LEITE. LEITE, L.; ESTEVES, E. Ensino orientado para a Aprendizagem Baseada na Resolução de Problemas na Licenciatura em Ensino da Física e Química. In: CONGRESSO GALAICO-PORTUGUÊS DE PSICOLOGIA. 8., 2005, Braga. Anais [...] Braga: CIED, 2005. p. 1751-1768.

MANTOVANI, S. R. Sequência didática como instrumento para a aprendizagem significativa do efeito fotoelétrico. 2015. 116 f. Dissertação (Mestrado em Ensino de Física) Faculdade de Ciências e Tecnologia, Universidade Estadual Paulista, Presidente Prudente.

MITRE, S. M. Metodologias ativas de ensino-aprendizagem na formação profissional em saúde: debates atuais. Ciência \& Saúde Coletiva, Rio de Janeiro, v.13, p 2133-2144, nov. 2008. Supl. 2.

OLIVEIRA, R. A. L. C. Aprendizagem Baseada em Problemas e o ensino do conceito de geração de energia elétrica. 2019. 115 f. Dissertação (mestrado) - Universidade Estadual Paulista (Unesp), Faculdade de Ciências e Tecnologia. Presidente Prudente, SP. 2019.

REDISH, E. F. Teaching physics with the physics suite. 1. ed. NJ: John Wiley \& Sons. 2003.

RICHARDSON, R. J. Pesquisa Social: Métodos e Técnicas. São Paulo: Atlas, 2011.

SÁNCHEZ-RODRÍGUEZ, J.; RUIZ-PALMERO, J.; SÁNCHEZ, E. V. Las clases invertidas: beneficios y estrategias para su puesta en práctica en la educación superior. In: Congreso 
internacional de tecnologías para la educación y el conocimiento y de pizarra digital: diversidad, estrategias y tecnologia, 19., 2014, Madrid. Anais [.... Málaga: Repositorio Institucional Universidad De Málaga, 2014, p 1-11. Disponível em: http://hdl.handle.net/10630/7821. Acesso em: 25 mai. 2021.

SOUZA, S. C.; DOURADO, L. Aprendizagem Baseada em Problemas (ABP): um método de aprendizagem inovador para o ensino educativo. Holos, Rio Grande, v. 5, p. 182-200, set. 2015.

ZABALA, A. A prática educativa: como ensinar.1. ed. São Paulo, Editora Artmed, 1998. 224 p.

Submetido em: 01 de mar. de 2021.

Aprovado em: 19 de abr. de 2021.

Publicado em: 19 de mai de 2021. 